\title{
Thyroxine replacement treatment and osteoporosis
}

\author{
Controversy continues about the optimum dosage
}

Hypothyroidism affects at least $1.4 \%$ of women of all ages in Britain, ${ }^{1}$ and the prevalence rises to $5 \%$ when people of both sexes over 60 years old are investigated. ${ }^{2}$ Thyroxine is widely prescribed both for hypothyroidism and for conditions in which the indications are less clear-for example, a follow up study of the Framingham cohort in the United States showed that $15 \%$ of those taking thyroid hormone did so for conditions such as obesity or fatigue.

Thyroxine may not, however, be a harmless preparation, nor should it be prescribed as some sort of placebo. Recent research has suggested that the dosage of thyroxine should be considered carefully. Patients receiving thyroxine in conventional doses (100-200 $\mu$ g a day) often have raised serum total and free thyroxine concentrations. ${ }^{+}$In addition, since the introduction of more sensitive assays for thyroid stimulating hormone (which can distinguish normal from reduced concentrations) it has become clear that many patients receiving thyroxine have thyroid stimulating hormone concentrations that are below the lower limit of normal or are so suppressed as to be undetectable. ${ }^{56}$ What is not clear is whether such patients, who rarely have any features of hyperthyroidism, have adverse effects related to their excess of thyroxine. ${ }^{7}$ Patients with hypothyroidism who are receiving thyroxine may have abnormal systolic time intervals ${ }^{8}$ and raised activities of liver derived plasma glutathione $S$-transferase similar to patients with thyrotoxicosis ${ }^{9}$; these findings are claimed by some workers (though not by ourselves ${ }^{10}$ ) to be evidence of potentially harmful consequences of excess thyroxine.

Thyrotoxicosis has long been recognised as a risk factor for osteoporosis. ${ }^{11}$ Recent studies have suggested that exogenous thyroxine may predispose patients to osteoporosis in the same way as endogenous hyperthyroidism. Ross et al examined bone density in 28 premenopausal women who had been taking thyroxine for five or more years (mean dose $171 \mu \mathrm{g}$ a day); thyroid stimulating hormone was suppressed in $23 .^{12}$ Women who had taken thyroxine for 10 or more years had a $9 \%$ reduction in bone density compared with age matched controls without thyroid disease, leading the authors to conclude that prolonged suppressive treatment with thyroxine may result in mild subclinical hyperthyroidism with adverse effects on bone. They recommended that patients should be given the smallest dose of thyroxine to achieve a satisfactory clinical response. Paul et al reported a $13 \%$ lower bone density at the femoral neck and a $10 \%$ lower bone density at the femoral trochanter than in controls in
31 premenopausal women treated with thyroxine for a minimum of five years. ${ }^{13}$ These authors, too, recommended a dosage of thyroxine "that is carefully monitored to avoid the long term use of dosages that are excessive." Not surprisingly, these findings and conclusions prompted editorial comment in the Fournal of the American Medical Association ${ }^{14}$ and extensive discussions at the 1989 meeting of the American Thyroid Association, with most people favouring a reduction of thyroxine dosage and repeated measurements of thyroid hormone and thyroid stimulating hormone concentrations.

The authors of these studies of bone density in patients treated with thyroxine have proposed fundamental changes in prescribing for patients with hypothyroidism, as well as in biochemical monitoring. These changes would cost a lot besides inconveniencing patients, so we should remember that several questions remain unanswered. For example, is reduced bone density confined to premenopausal women treated with thyroxine or are postmenopausal women and men affected similarly? Are there clear cut differences in risk in those treated with suppressive doses compared with those with thyroid stimulating hormone concentrations within the normal range? What is the clinical relevance of small but significant decreases in bone density? Do they increase the risk of fractures?

Of perhaps greater importance are the potential consequences of reducing the dose of thyroxine in patients given conventional treatment but found on biochemical testing to have raised thyroxine or reduced thyroid stimulating hormone concentrations. Might reducing the dose of thyroxine then lead to undertreatment, or might treatment be withheld in those with mild biochemical abnormalities? Undertreatment with thyroxine is already common, as indicated by a recent study that showed that no fewer than $37 \%$ of patients with definite hypothyroidism had a clearly raised thyroid stimulating hormone concentration $(>10 \mathrm{mU} / \mathrm{l})$ despite treatment with thyroxine. ${ }^{3}$ Overt hypothyroidism is known to be associated with abnormalities in lipid metabolism that may predispose patients to accelerated coronary artery disease. ${ }^{15}$ The association between mild hypothyroidism and hyperlipidaemia and of these with coronary artery disease is less clear cut, though subclinical hypothyroidism (raised thyroid stimulating hormone concentrations with normal thyroxine concentrations) has been proposed as a risk factor for coronary artery disease. ${ }^{1617}$ Moreover, our own preliminary prospective study of the effect of thyroxine replacement in patients with mild 
asymptomatic thyroid failure showed that they had initially raised serum total cholesterol concentrations, which fell with treatment with thyroxine ${ }^{18}$; the serum cholesterol concentration was also higher when the thyroxine dose was such that the thyroid stimulating hormone concentration was within the normal range than when it was suppressed to below normal. ${ }^{18}$ These findings suggest that reducing thyroxine dosage in patients being treated for hypothyroidism may exchange an increased risk of osteoporosis and bone fracture for an increased risk of hypercholesterolaemia and coronary artery disease-hypotheses that require examining in more patients of both sexes and different ages.

What advice can be given in our present state of knowledge? We believe that it is wise to avoid prescribing higher than conventional doses of thyroxine for hypothyroidism unless suppression of thyroid stimulating hormone is important, as

1 Tunbridge WMG, Evered DC, Hall R, et al. The spectrum of thyroid disease in a community: the Whickham survey. Clin Endocrinol 1977;7:481-93.

2 Parle J, Franklyn JA, Jones S, Sheppard MC. Prevalence of thyroid dysfunction in old age; screening in general practice of 1210 patients aged 60 years and over. $f$ Endocrinol (in press).

Sawin CT, Geller A, Hershman JM, Castelli W, Bacharach P. The ageing thyroid. The use of thyroid hormone in older persons. FAMA 1989;261:2653-5.

Pearce CJ, Himsworth RL. Total and free thyroid hormone concentrations in patients receiving maintenance replacement treatment with thyroxine. $\mathrm{Br}$ Med $\mathcal{F}$ 1984;288:693-5.

Franklyn JA, Black EG, Wilson EM, Davis JRE, Sheppard MC. Limitations of a sensitive assay for TSH in the management of thyroid disease. Clin Chem 1988:34:991.

6 Ross DS, Ardisson LJ, Meskell MJ. Measurement of thyrotropin in clinical and subclinical hyperthyroidism using a new chemiluminescent assay. $\mathcal{F}$ Clin Endocrinol Metab 1989;69:684-8.

Toft AD. Thyroxine replacement treatment: clinical judgment or biochemical control? $\mathrm{Br}$ Med $\mathrm{F}$ 1985;291:233-4.

8 Jennings PE, O'Malley BP, Griffin KE, Northover B, Rosenthal FD. Relevance of increased serum thyroxine concentrations associated with normal serum triiodothyronine values in hypothyroid patients receiving thyroxine: a case for "tissue thyrotoxicosis." Br Med F 1984;289:1645-7.

9 Beckett GJ, Kellett HA, Gow SM, Hussey AJ, Hayes JD, Toft AD. Raised plasma glutathione $S$-transferase values in hyperthyroidism and in hypothyroid patients receiving thyroxine replacement: evidence for hepatic damage. Br Med f 1985;291:427-31. in patients with a history of carcinoma of the thyroid; steps should be taken to ensure long term compliance with thyroxine and to avoid undertreatment, and that entails occasional biochemical monitoring with adjustment of the dose of thyroxine when necessary. The question that cannot yet be answered, we believe, is whether maintenance of thyroid stimulating concentrations within the normal range should be the prime objective for clinicians who prescribe thyroxine-as is increasingly the practice in North America.

J A FRANKLYN Senior Lecturer in Medicine

M C SHEPPARD

University of Birmingham

Queen Elizabeth Hospital,

Birmingham B15 2TH

10 Franklyn JA, Sheppard MC. Tissue thyrotoxicosis. Br Med f 1985;290:391.

11 Plummer WA, Dunlap HF, Moore AB. Cases showing osteoporosis is due to decalcification in exophthalmic goiter. Staff Meetings of the Mayo Clinic 1928;3:119-21.

12 Ross DS, Neer RM, Ridgway EC, Daniels GH. Subclinical hyperthyroidism and reduced bone density as a possible result of prolonged suppression of the pituitary-thyroid axis with L-thyroxine. Am f Med 1987;82:1167-70.

13 Paul TL, Kerrigan J, Kelly AM, Braverman LE, Baran DT. Long-term L-thyroxine therapy is associated with decreased hip bone density in premenopausal women. JAMA 1988;259: 3137-41.

14 Cooper DS. Thyroid hormone and the skeleton: a bone of contention. FAMA 1988;259:3175.

15 Becker $C$. Hypothyroidism and atherosclerotic heart disease: pathogenesis, medical management, and the role of coronary artery bypass surgery. Endocr Rev 1985;6:432-40.

16 Bastenie PA, Bonnyns $M$, Vanhaelst L. Grades of subclinical hypothyroidism in asymptomatic autoimmune thyroiditis revealed by the thyrotrophin-releasing hormone test. $\mathcal{F}$ Clin Endocrinol Metab 1980;51:163-6.

17 Tunbridge WMG, Evered DC, Hall R. Lipid profiles and cardiovascular disease in the Whickham area with particular reference to thyroid failure. Clin Endocrinol 1977;7:495-508.

18 Hughes EA, Franklyn JA, Ratcliffe JG, Smith SC, Black EG, Sheppard MC. Treatment of asymptomatic hypothyroidism and hypercholesterolaemia. F Endocrinol 1989;121(suppl): 93.

\title{
Screening elderly patients
}

\author{
A task well suited to health visitors?
}

As long as 25 years ago a study on elderly patients in general practice alerted us to the many who were suffering from disorders that were not reported to or identified by their doctors. ${ }^{1}$ Despite vast developments in practice organisation and in the care of the elderly since then, serious disorders still often go unrecognised. Some recent practice surveys found that only two fifths of patients over 75 with acute depression were receiving treatment and that less than three quarters of patients with moderate or severe dementia had had their problem identified by a general practitioner. ${ }^{23}$ Other studies have found that only two fifths of people over 80 with painful feet were receiving chiropodical treatment; that only a third of people with dental problems in sheltered housing perceived a need for treatment; and that many deaf people in residential care had wax in their ears, had not had audiological assessment, or had hearing aids that were not working. ${ }^{+6}$

Despite such evidence of unresolved need in the elderly screening programmes have achieved only modest benefits. ${ }^{7-9}$ These have included a reduction in the amount of time spent in hospital, a lower mortality, and tenuous evidence of improved morale and self esteem. Screening has not been shown to alter the frequency of socioeconomic, function, or medical disorders or the severity of physical disability, anxiety, or depression. Furthermore, programmes are expensive, initially requiring the equivalent of 18 hours a week of health visitor work for a practice with 4000 patients of all ages. ${ }^{10}$ Despite this and despite the fact that screened patients are more likely to be referred to social or health agencies a screening programme in Scandinavia cut by half the cost of care for people over 75. Studies in other countries with different systems of social and health care would be required to validate this figure.

These uncertainties help explain why in the mid 1980s a postal questionnaire found that only $37 \%$ of general practitioners, $59 \%$ of geriatricians, and $33 \%$ of professors of general practice thought that screening was necessary for the adequate care of old people. ${ }^{11}$ Furthermore, a cheaper and equally effective way of collecting information on old people is to record it as part of a patient initiated consultation. ${ }^{12}$ This technique has provided contact with more than $90 \%$ of patients over 75 in some practices. ${ }^{13}$ It is then a simple task to arrange for the screening of the remaining $10 \%$.

The new general practice contract requires a member of the practice to visit patients over 75 each year, and health visitors might be well suited to this task. ${ }^{8}$ Many studies have shown that they can identify the health and social needs of the elderly effectively and report these to general practitioners. If health visitors are to take on this aspect of the care of the elderly, however, many more will be needed.

Opinions vary as to what information should be collected as part of a screening programme, but some of the more important items are social contacts, mobility, nutrition, house safety, awareness of welfare services, availability of carers, continence, housing, awareness of benefits, hearing, personal 